\title{
Overcoming the Stereotypes of Masculinity in Singaporean Elite Level Male Gymnasts
}

\author{
Ilma Nur Jannah Binte Fadzal' ${ }^{1}$ Ho Jin Chung ${ }^{2^{*}}$ \\ ${ }^{1}$ Nanyang Technological University, Singapore \\ ${ }^{2}$ National Institute of Education, Nanyang Technological University, Singapore
}

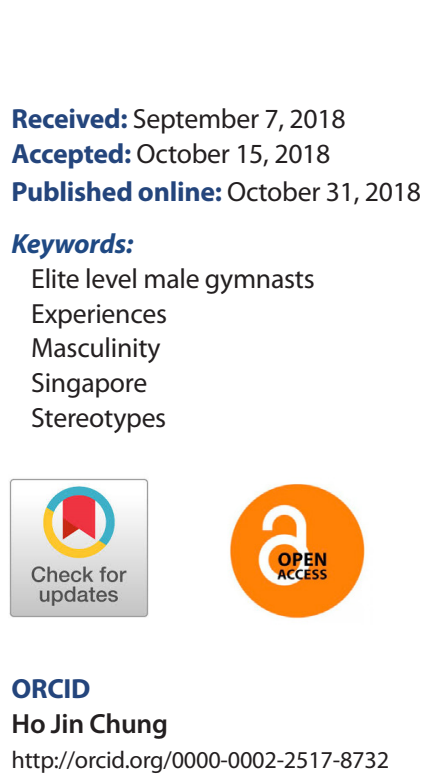

http://orcid.org/0000-0002-2517-8732

\begin{abstract}
OBJECTIVES The purpose of this study was to provide detailed accounts of the experiences faced by elite male gymnasts in overcoming stereotypes of masculinity in Singapore.

METHODS An empirical phenomenological approach was employed and Semi-structured interviews were conducted with five Singaporean elite level male gymnasts from the Singapore Gymnastics Association. All interviews were transcribed verbatim before being analysed into raw themes, categories and general dimensions.

RESULTS EPrior-entry into gymnastics, participants reported the initial exposure of gender stereotypes in the realm of sports. Masculinity was revealed to be a constructed and learned concept after being socially exposed to different cultures, roles and norms. After overcoming societal expectations post-entry into gymnastics, participants exhibited very personalized views on the construct of gender and masculinity despite being aware of the established norms upheld in society. The acceptance of identity was manifested through the encapsulation of masculinized traits that reinstated conformity to society's definition of masculine, despite the possession of personalized views on gender constructs.

CONCLUSIONS The study provides a significant contribution to the concepts of sport and masculinity, through its investigation of Singaporean elite gymnasts within Singapore. The positive experiences can be used as a benchmark to incorporate and promote gender fluidity whereas negative experiences can be used as a platform for future changes of gender stereotypes in the realm of sports.
\end{abstract}

( ) The Asian Society of Kinesiology and the Korean Academy of Kinesiology

\section{Introduction}

The concepts of sex and gender are often used interchangeably yet they possess very different meanings [4]. According to Bem [2], sex classifies under biological differences between males and females while gender endorses traits and behaviours

\footnotetext{
*Correspondence: Ho Jin Chung, Physical Education and Sports Science, National Institute of Education, Sport Science and Management, Nanyang Technological University, 1 Nanyang Walk, Singapore, Singapore

E-mails: hojin.chung@nie.edu.sg
}

that characterise males and females. On the other hand, Butler [39] argued the following:

Gender is not to culture as sex is to nature; gender is also the discursive/cultural means by which "sexed nature" or "a natural sex" is produced and established as "prediscursive," prior to culture, a politically neutral surface on which culture acts.

Despite sharing similarities, sex stereotypes and gender roles are not identical as stereotypes entail descriptions while

(1) This is an open-access article distributed under the terms of the Creative Commons Attribution License (http://creativecommons.org/licenses/by-nc/4.0/), which permits unrestricted use, distribution, and reproduction in any medium, provided the original work is properly cited. 
gender roles refer to prescriptions [4]. As such, men have been stereotyped into specific roles that emphasize on physical and emotional capabilities, muscular definition and physical size, and the potential to succeed in sports [9]. Past studies have shown that gender identity has a direct relation to sport participation, of which masculinity is deemed positive in relation to the endorsement of athletic identity whereas femininity is considered negative [21]. These studies confirm that sports lean towards a masculine domain and that athletes typically endorse masculine traits.

Beyond gender identity, through the concept of gender schema, behaviours could be determined by an individual's conformity to societal expectations [2]. Gender schema functions as cognitive filters that allow for the interpretation of events, while orienting behaviours based on the cultural difference between males and females [4]. Through the use of gender to encode and organise information, sex-typed individuals (i.e. masculine males and feminine females) typically choose activities that conform to their sex more than non-sextype individuals (i.e. androgynous and undifferentiated males and females). Sex-type individuals were also more likely to associate masculine traits to participants in masculine sports and feminine traits to participants in feminine sports [23]. Generally, as compared to non sex-typed individuals, sex-type individuals tended to use sex stereotypes when judging others, conformed to stereotypes and normally avoided sex-inappropriate behaviours [4].

For a long time, sports have been considered a setting for masculine behaviour development [30]. The belief that sports attributed to character building in men was readily accepted by society back in the 1960s, with sports regarded as a medium to instill important values, attitudes and skills [48]. Even before then, there have been significant evidence of sports fostering values such as strength and bravery, which were deemed essential in national defence $[47,54,55]$. Emphasis was also put on organised sports to incorporate "manly" behaviours and values into males as competitive sports were a means to teach boys how to be tough while men were moulded to fit dominant forms of masculinity [47]. Through these sports, it conveyed that the bodies of men were able to endure physical punishment and violence that represented their superiority to the bodies of women by the notion of hegemonic masculinity [38]. According to Connell [41], hegemonic masculinity was represented as male dominance and the oppression of femininities, and the subordination and marginalisation of masculinities. Development of male solidarity through sports paved the opportunity for men to identify with one another, provided regular rehearsal of masculine identification and reinforced masculine identification and solidarity [55].

Gymnastics is a sport commonly known to be "feminine appropriate" and reserved for the female gender [27]. Society has expected gymnastics to be a beacon of grace, artistry and beauty for a considerable amount of time after its recognition as a sport [10]. Despite being labelled as a feminine appropriate sport, it also entails that women have come a long way since their marginalization in the realm of sport, to which has been long regarded as more of a masculine domain [28]. Sports in general have been categorised into different orientations, structured for specific genders such as masculine, feminine or gender-neutral $[15,23]$. Expressive sports like gymnastics are categorised as a feminine sport, swimming or tennis as neutral sports, and fighting activities as masculine sports $[18,28]$. Sports are deemed as masculine or feminine based on their degree of masculinity or femininity characteristics where masculine sports include physical contact, face-to-face opposition, strength, or aggression while feminine sports include expressivity, grace, or aesthetics [15].

Numerous studies have explored the experiences of women in conventionally masculine sports: Mennesson [24] has focused on boxing, Sisjord and Kristiansen [35] on wrestling, Dorken and Giles [8] on ice-hockey, Roster [29] on motorcycling and Scraton et al. [34] on football. However, there is a lack of research focusing on male participation in female dominated sports. There is a need to examine the lived experiences of men and the sociological implications of masculinity. This would generate a more comprehensive understanding of the association between the male identity and the sport they choose, and the process of masculinity in which they experience prior and post-entry into the sport. The purpose of this study is to investigate the experiences overcoming the stereotype of masculinity in Singaporean elite level male gymnasts through determining what an experience means for the per- 
sons who have had the experience. The current study is important as it will analyse men in a social setting that has long been regarded as a feminine domain.

\section{Methods}

\section{Phenomenological Interview}

The phenomenological method, devised by Husserl [44] is an empirical method that solely focuses on the lived experiences of an individual, directed exclusively to describing the experience in its essence [52]. Due to its rich and descriptive accounts of an individual's lived experiences, the phenomenological interview is proposed to be one of the most powerful techniques that enables the participant to take form as the expert [52]. Descriptions provided by the participants formed a foundation for deliberate analysis to exhibit the essences of the experience. The descriptive phenomenological approach was chosen for the study as it involves a return to experience with the hopes to comprehend descriptions that provide the basis for a reflective structural analysis [51]. In accordance to previous recommendations of phenomenological interviews, the interviews conducted with the elite gymnasts lasted between thirty to forty-five minutes [7].

The principles of phenomenology as proposed by Moustakas [51] were followed closely to ensure consistency for all interviews. The interviews were semi-structured in nature, exhibiting a certain degree of basic structure with flexibility and freedom given to the co-investigator and participants during the interview, whilst ensuring that the participants remain within the context of study. All interviews consisted with a prior and post-entry into gymnastics experience description. Under prior-entry to gymnastics, all interviews started with the question "Tell me how you developed the interest in gymnastics", which allowed the participants the freedom to focus on their personal experience. Under post-entry to gymnastics, all interviews started with the question "Tell me how you view yourself after taking up gymnastics", which magnified on their lived experience after joining gymnastics. Follow-up questions were also asked to continue the flow of conversation with probes being used as needed to understand more in depth of the athletes' experiences.

\section{Participants}

Five elite Singaporean male gymnasts aged between seventeen to twenty-three years old (Mean $=20.2, \mathrm{SD}=2.28$ ) were recruited having met the following three inclusion criteria: 1) Participants are current members of Singapore Gymnastics Association during the course of the study, 2) participants identify themselves as males and 3) participants are willing and able to describe their experiences clearly. Purposive sampling [53] was used to obtain experiences both prior and post entry into gymnastics. All participants were briefed about the nature of the study and given assurances of confidentiality should they agree to participate. Moreover, all participants agreed to participate in the study and submitted a written consent. Also, participants under the age of twenty-one were advised to seek the consent approval from their parents or guardians.

\section{Data Collection}

Following ethics approval by NTU IRB (IRB 2017-07028), the co-investigator contacted all five participants and arranged for each interview to be conducted. Each interview was recorded in an empty multi-purpose hall near the Singapore Gymnastics Association, using a voice recorder, at a time convenient for the elite athletes. Participants were offered the choice to have the interviews conducted at the comfort of their homes but due to their hectic training schedules, an empty hall within vicinity of their training ground was utilized for convenience.

Prior to the start of each interview, participants were briefed of their right to withdraw from the study without penalty or prejudice. The interviews were recorded and listened to closely, transcribed verbatim, read and thematically analysed. Epoche, the bracketing of prejudgment, preconceived ideas and biases was also exercised to neglect previous commitments and knowledge for the attainment of a "purified" consciousness [51].

The structure of the experience was then described based on the researcher's opinion and judgement derived from the participants' described responses. As themes emerged and became more explicit, transcripts were revisited. Member checking [42], a technique involving the meeting of partic- 
ipants for a follow-up session, was also utilized to allow for the conclusion of rich and descriptive accounts of athletes' lived experiences. It is widely considered as a good method to establish a credible and accurate presentation of the interpretations [6]. Each participant was provided with the full interview transcript and its interpretations to which they were given the opportunity to verify the accuracy of the transcripts and to confirm the interpretations. According to Sandelowski [31] a sample of an adequate size generally permits a deep, case-oriented analysis that results in a new and richly textured understanding. This is also closely related to the concept of saturation, to which is a point where no new data is generated. To ensure that saturation had occurred, the co-investigator would urge the participants further by asking "Is there anything else that you would like to add?" [40].

\section{Data Analysis}

Interviews were transcribed verbatim before being read multiple times through the process of indwelling [49]. All five participants separately and independently analysed the interview transcripts to enhance trustworthiness and credibility. A consistent process of data analysis that reflected a flexible and inductive content approach was used to generate themes. These themes were then analysed intently to form meaning units or potential underlying thematic phrases [51]. Thematic ideas emerged from the research clustered and further defined to make sense of the experienced lived, while producing initial discovery sheets of key words and concepts. Independently, the authors provisionally grouped common concepts into categories. The authors compared categories and agreed on general dimensions. There was a high level of agreement between researchers concerning the general dimensions, and where minor disagreement existed relating to categories, the transcripts were re-examined, and coding decisions discussed.

\section{Results}

Data representation in the following section is in accordance with recommendations on qualitative data representation [11]. Through the process of thick description [56]. it allows the data to speak for itself, with quotes from the interviews as a way to highlight participant voices. Data separated broken into two distinct aspects of experiences. Firstly, the experience prior-entry into gymnastics portrayed the initial occurrences encountered by the participants before joining gymnastics (Table 1). Secondly, the experience post-entry into gymnastics portrayed the subsequent events encountered by the participants after joining gymnastics (Table 2). The results are arranged based on the chronological order of a conflict experience, and each participant is distinguished by a number.

\section{Sustained participation due to fun}

All participants experienced an early induction into gymnastics with ages ranging from as early as three years old up until eight years old. The experience and description of age appeared to exhibit youth and a norm to the gymnasts, with a bias towards entering gymnastics at a young age. As Participant 1 recalled, "I mean those elite gymnasts they will start like pretty young, like five or six years old", confirming that the age induction into the sport of gymnastics is known to be very early. Participant 1 even expressed regret having entered gymnastics at a later age of eight years old while being aware that elite level gymnasts enter gymnastics about two or three years younger than him. Despite the negative reception of early specialisation [12], participants exhibited an inclination to start gymnastics as early as possible. Participants tended to describe gymnastics as a very fun sport. The movements that include flipping and swinging were considered an influential element in the fun component of their experience.

I thought it was very cool to learn how to flip and stuff. (Participant 2)

The concept of fun was apparent in the participants' inclination towards gymnastics, crediting that the enjoyment experienced piqued their interests, regardless of any perceptions associated with gymnastics. Previous studies have shown that positive movement experiences were vital in sustaining participation in physical activity in children [1] while "fun" was identified as the leading reason for participation in sports teams $[26,34]$. 
Table 1. Thematic analysis on the experiences prior-entry into gymnastics

\begin{tabular}{|c|c|c|}
\hline Raw Themes & Categories & $\begin{array}{c}\text { General } \\
\text { Dimensions }\end{array}$ \\
\hline I mean those elite gymnasts they will start like pretty young, like five or six years old & \multirow[t]{5}{*}{ Early induction } & \multirow{10}{*}{$\begin{array}{l}\text { Sustained participation due } \\
\text { to fun }\end{array}$} \\
\hline But like when we were seven and eight there's like gymnastics class & & \\
\hline At that point of time I was very young & & \\
\hline I mean I was like seven years old & & \\
\hline When I just started I was like eight years old & & \\
\hline $\begin{array}{l}\text { Ever since then it slowly like got onto me ah like it's actually quite fun to be like flipping around and } \\
\text { like swinging on the bars }\end{array}$ & \multirow[t]{5}{*}{ Fun component } & \\
\hline I was just quite excited I thought it was like very cool to learn how to flip and stuff & & \\
\hline I just saw that gym looked fun and then I just joined it for the sake of it being fun & & \\
\hline I just thought that it was a lot of fun & & \\
\hline I didn't really like thought about it I just like, I just thought it was fun and like I just joined the CCA & & \\
\hline $\begin{array}{l}\text { So that was my first experience of like being stereotyped as like, joining gymnastics and like being } \\
\text { more feminine and all that }\end{array}$ & \multirow[t]{9}{*}{$\begin{array}{l}\text { Awareness of feminine } \\
\text { sports }\end{array}$} & \multirow[t]{9}{*}{$\begin{array}{l}\text { Stereotypes of gender roles } \\
\text { in gymnastics }\end{array}$} \\
\hline Like woman and rhythmic I just thought it was just gymnastics, so I joined & & \\
\hline $\begin{array}{l}\text { I did have apprehensions to joining gym mainly because not a lot of guys join gym in my school (like } \\
4-5 \text { guys) }\end{array}$ & & \\
\hline I really didn't know what gymnastics was I thought like anyone could do it like male or female & & \\
\hline I knew that you know some people would think that it's more of a feminine sport & & \\
\hline $\begin{array}{l}\text { When like my cousin like the same age they see me wearing all these tight-fitting clothes and all so } \\
\text { they started teasing me and all that }\end{array}$ & & \\
\hline Like woman and rhythmic I just thought it was just gymnastics, so I joined & & \\
\hline $\begin{array}{l}\text { Actually, most of the time people would think that it's for girls and yeah, it's a really girly sport and } \\
\text { they play with ribbons and stuff }\end{array}$ & & \\
\hline I thought it was really like girly stuff & & \\
\hline It was more of a like a family affair like my whole family is in gymnastics & \multirow[t]{3}{*}{ Direct influence } & \multirow[t]{5}{*}{ Family support system } \\
\hline $\begin{array}{l}\text { They were fine with it cause like my dad was an army friend with the coach then so they were quite } \\
\text { supportive then I was quite active as a kid so they decided to just let me join the sport }\end{array}$ & & \\
\hline At first, when I first joined in primary school my older brother was already inside gymnastics & & \\
\hline $\begin{array}{l}\text { All I could tell was that they were supportive like they would bring me to class and they were happy } \\
\text { that I had a sport to do }\end{array}$ & \multirow[t]{2}{*}{ Support from loved ones } & \\
\hline Only parents were like close to me like so like they were supportive of me doing gymnastics & & \\
\hline I mean when I took gymnastics I was still quite young & \multirow[t]{4}{*}{ Innocence } & \multirow{8}{*}{$\begin{array}{l}\text { Ignorance towards societal } \\
\text { construct of masculinity }\end{array}$} \\
\hline It didn't really make a different cause I was quite young at that time & & \\
\hline I mean I was like 7 years old so I mean I don't know what manliness was & & \\
\hline I guess when I started gym I was still young & & \\
\hline So like being manly and like feminine wasn't really like taken into consideration & \multirow{4}{*}{$\begin{array}{l}\text { Ignorance towards societal } \\
\text { norm }\end{array}$} & \\
\hline $\begin{array}{l}\text { I didn't really know there was like, different types of like there's like woman and rhythmic I just } \\
\text { thought it was just gymnastics so I joined and I didn't know much }\end{array}$ & & \\
\hline So I don't think I knew anything about the perception of manliness & & \\
\hline Didn't think much about masculinity & & \\
\hline
\end{tabular}

I just joined it for the sake of it being fun. (Participant 3)

\section{Stereotypes of gender roles in gymnastics}

Participants displayed naivety from their initial exposure to the different gender-appropriate sports and the associat- ed gender roles. Participant 1 mentioned that it was the first time that he was stereotyped as someone who joined a female dominated sport and was perceived as more feminine. In addition, coming into terms with how sports were distinguished into different gender categories appeared to be a 
completely new experience for the participants.

I really didn't know what gymnastics was I thought like anyone could do it like male or female”. (Participant 5)

Participants also reported that they were branded as those who participated in a girly sport. Comments and feedback from persons outside of gymnastics (i.e. outsiders) were reflected to associate girly aspects to gymnastics such as ribbons, dancing and ballet, all of which form of the artistic and expressive components in gymnastics that are commonly associated to femininity $[15,23]$.

Actually, most of the time people would think that it's for girls and yeah, it's a really girly sport and they play with ribbons and stuff. (Participant 4)

\section{Family support system}

Participants described their entry into gymnastics as a result of the exposure from their siblings or close family friends. To have a relationship with someone who has deviated from the norm of pursuing a socially accepted sport appeared to relinquish fear while stimulating participation.

At first, when I first joined in primary school my older brother was already inside gymnastics. (Participant 4)

Participants reported receiving support from loved ones on their decision to pursue gymnastics. Through the approval from family members of the choice of sport, there appears to be a dismissal of conformance to societal expectations.

All I could tell was that they were supportive like they would bring me to class and they were happy that I had a sport to do. (Participant 3)

Gymnastics, in its essence, is a sport, regardless of gender appropriateness. Frequent participation in exercise has been proven to promote health and prevent diseases, [37] and is also a contributing factor to many physical and psychological benefits [14]. A strong family support system showcased a tendency to advocate participation in general sports rather than an emphasis in a specific gender-appropriate sport.

\section{Ignorance towards societal construct of masculinity}

Participants described that they were all very young prior-entry into gymnastics. Due to this, the participants displayed innocence towards the societal norm that they joined a female-dominated sport. When questioned about their thoughts on manliness, they exhibited unawareness of the concept of masculinity and its existence in the realm of sport.

I mean I was like seven years old so I mean I don't know what manliness was (Participant 2)

With innocence, comes ignorance where participants reported obliviousness in the concept of masculinity when choosing the sport of gymnastics.

I didn't really know there was like, different types of like there's like woman and rhythmic I just thought it was just gymnastics so I joined and I didn't know much. (Participant 2)

Despite being considered a masculine domain [45, 20, 33], some sports are deemed more appropriate for women and others for men. Koivula [19] reported that societal perceptions of feminine sports were associated to the concepts of aesthetics, low-risk and gracefulness whilst masculine sports were related to danger, strength and speed. These concepts, however, appeared non-existent to the participants as they credited the sport of gymnastics in itself as the driving factor in their sport selection.

\section{Media authority on gender constructs}

Participants described the feedback and comments received from outsiders as doubtful and uncertain. These descriptions showcased a lack of gymnastics awareness, which confirmed that gymnastics, at least in a Singaporean context, is still relatively new.

Some people really have no idea what gymnastics is all about. (Participant 1) 
Table 2. Thematic analysis on the experiences post-entry into gymnastics

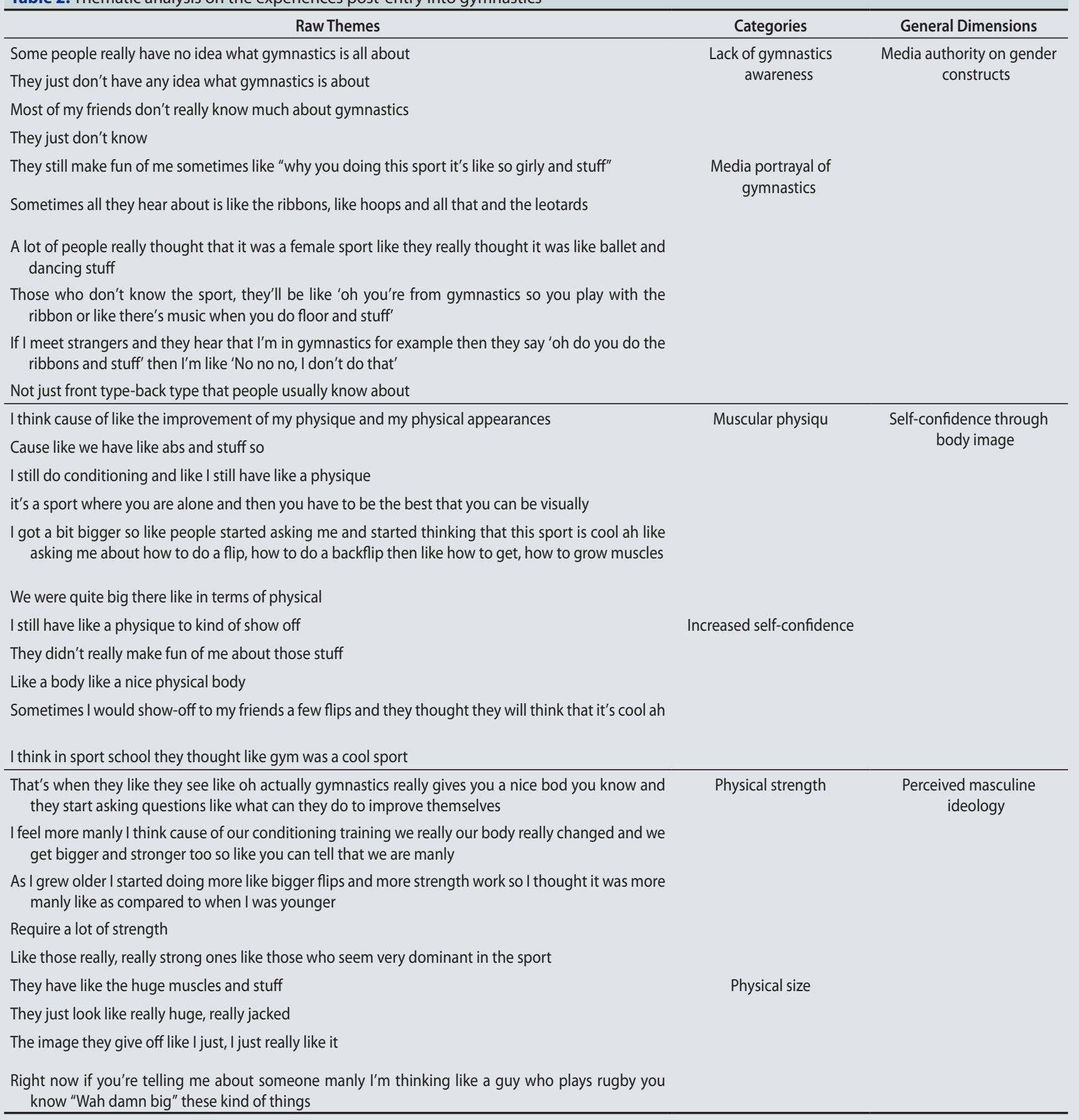

Participants reported receiving rather biased responses from outsiders towards their association with the female aspect in gymnastics. Many held the perception that gymnastics was a "female sport" and that participants engaged in the same events as female gymnasts.
Sometimes all they hear about is the like the ribbons, like hoops and all that and the leotards. (Participant 3)

The media has authority on gender construction, which is easily internalised by society due to the limited knowledge in 
Table 2. Thematic analysis on the experiences post-entry into gymnastics (Cont.)

\begin{tabular}{|c|c|c|}
\hline Raw Themes & Categories & General Dimensions \\
\hline $\begin{array}{l}\text { They start asking questions like what can they do to improve themselves. So that's where they } \\
\text { try to learn from me on how to like to make their body feel more manly in this term }\end{array}$ & Pride in gymnastics & $\begin{array}{l}\text { Overcoming societal } \\
\text { expectations and norms }\end{array}$ \\
\hline \multicolumn{3}{|l|}{ I would show-off to my friends a few flips and they thought they will think that it's cool ah } \\
\hline \multicolumn{3}{|l|}{$\begin{array}{l}\text { I didn't have any issues with outside like others perceiving me as a gymnast like I'm totally } \\
\text { comfortable with it }\end{array}$} \\
\hline \multicolumn{3}{|l|}{$\begin{array}{l}\text { I mean, for gymnastics, it doesn't matter lah what I feel. Like, how I feel about gym is, I don't get } \\
\text { where the sense of it not being manly is but because it's more on like artistry }\end{array}$} \\
\hline \multicolumn{3}{|l|}{$\begin{array}{l}\text { I really didn't know what gymnastics were I thought like anyone could do it like male or female } \\
\text { yeah }\end{array}$} \\
\hline I know I'm a man & Acceptance of identity & \\
\hline \multicolumn{3}{|l|}{ I don't really need to change other people's perception } \\
\hline \multicolumn{3}{|l|}{ I mean, you want to think what you want to think then just think ah you know I'm just over here } \\
\hline \multicolumn{3}{|l|}{ I know how tough the sport is } \\
\hline \multicolumn{3}{|l|}{ Actually, I feel more manly } \\
\hline \multicolumn{3}{|l|}{ It didn't really affect me like how manly I can be or how manly it seems to be for other people } \\
\hline \multicolumn{3}{|l|}{$\begin{array}{l}\text { The fact of me wearing a leotard or being able to do splits that kind of thing doesn't like make } \\
\text { me think that I'm less of a man }\end{array}$} \\
\hline \multicolumn{3}{|l|}{$\begin{array}{l}\text { You just have to realise that being manly is not what society thinks now but it's just your own } \\
\text { thinking you know "do you think you're manly enough" well I would like to think so }\end{array}$} \\
\hline \multicolumn{3}{|l|}{$\begin{array}{l}\text { Like, honestly, I didn't really care what people said about me like whether it's like a girl's sport } \\
\text { or like feminine }\end{array}$} \\
\hline Through getting older then I've learnt to accept that and overcoming it & & \\
\hline
\end{tabular}

gymnastics. Women Artistic Gymnastics (WAG) events differ greatly as compared to Men Artistic Gymnastics (MAG). WAG includes vault, uneven bars, balance beam and floor, while MAG includes floor, pommel horse, still rings, vault and both parallel and horizontal bars. Participants described that outsiders assumed that they played with the ribbons and danced with music, which were mostly associated with WAG rather than MAG

\section{Self-confidence through body image}

Participation in sport has long been associated to a multitude of physical and psychological benefits such as strength, agility, coordination, increased resistance and improvement of self-confidence [36]. Participants tended to credit gymnastics for their muscular physique.

I got a bit bigger so like people started asking me and started thinking that this sport is cool ah like asking me about how to do a flip, how to do a backflip then like how to get, how to grow muscles. (Participant 5)

According to Drummond [9], the body affects the perception of oneself, others and the environment, constituting to the core of one's being and influencing social relations. Gender self-confidence is depends on the intensity of an individual's belief that he or she meets his or her personal standards for femininity or masculinity [16]. Participants recorded an increase in self-esteem through the muscular physique attained post-entry in gymnastics. Among their peers, the participants appeared more confident and even flaunted their physique, a body image they seemed proud of.

... like a body, like a nice physical body. (Participant 1)

I still have like a physique to kind of show off. (Participant 3)

\section{Perceived masculine ideology}

Participants associated the physical strength achieved from gymnastics to manliness. Through the physical condi- 
tioning and training that the participants underwent, participants showed an increase in physical strength, to which was affiliated to their perceived ideology of masculinity.

.. our body really changed and we get bigger and stronger too so like you can tell that we are manly. (Participant 2)

Participants reported physical size also had a relationship to manliness. From the physical conditioning and training they undergo, the bigger they become, the more they equate themselves to being more of a man.

Right now if you're telling me about someone manly I'm thinking like a guy who plays rugby you know "Wah damn big" these kind of things. (Participant 4)

Responses gathered from the participants further emphasized the continual existence of traditional male stereotype on physical capabilities, muscular definition and physical size.

\section{Overcoming societal expectations and norms}

What the participants gained from the experience might best be coined as pride in gymnastics. Participants reported a range of enhanced self-perceptions and a sense of satisfaction from gymnastics. Through comments and feedback made from outsiders about the improvement their physical bodies, the participants reported a sense of achievement.

They start asking questions like what can they do to improve themselves. So that's where they try to learn from me on how to like to make their body feel more manly in this term. (Participant 1)

All participants reported a sense of self-satisfaction in themselves that might have a direct relation to the acceptance of their identity. Despite joining a female-dominated sport, participants overcame the stereotypes typically associated with a girly sport. Moreover, the established expectations of outsiders did not influence the belief and viewpoints of the participants.

38 | The Asian Journal of Kinesiology
You just have to realise that being manly is not what society thinks now but its just your own thinking you know "Do you think you're manly enough?" well, I would like to think so. (Participant 4)

Like, honestly I didn't really care what people said about me like whether its like a girl's sport or like feminine. (Participant 5)

\section{Discussion}

\section{Experiencing the manifestation of gender stereotypes}

Based on the experiences of the participants, initial experience towards the manifestation of gender stereotypes were encountered in the early stages of their induction into gymnastics. Participants started to gain awareness in the different types of gender roles associated to different sports. As awareness had only started to become apparent, participants exhibited ignorance towards the societal construct of masculinity, reiterating that the concept of masculinity and femininity are learned. The participants reported to have experienced relatively negative external feedback on their choice of sport, of which further distinguished the line separating the different gender-appropriate sports. After reportedly being aware of the distinctions of gender-appropriate sports, participants reported an ignorance towards the societal construct of masculinity that encouraged men to identify with one another. This suggested that, as participants were of young ages prior-entry into gymnastics, innocence played a significant role in ignorance. It also portrayed that masculinity is socially constructed and learnt as one continues being socially exposed to the different cultures, roles and norms

\section{Gender portrayal and construction by media}

The media possesses authority on the construction of gender, of which are typically internalised by society due to limited knowledge in gymnastics. The media allows for the rapid communication of embedded messages with cultural norms [5] that keep expectations of gender roles such as attitudes and behaviours within these boundaries. As the audience process large amounts of messages about gender norms, it is likely the adherence idealized conceptualizations of gender roles would 
occur [43] from the comparison of oneself to the characters on television, music videos, video games and films [13].

A quantitative study by Billings and Eastman [3] revealed that commentary of artistic, subjective sports requiring judges such as gymnastics was more likely to contain gender biases, with a disparity in the commentary of male and female athletes. It reported significant differences in the way male and female gymnasts were described. Females were described as succeeding due to ability and experience while men were described to have succeeded based on concentration, courage and strength, of which portrayed a similarity in the traditional construction of masculinity in sport $[47,54,55]$. In terms of personality, men were being described as more emotional, and failure was attributed to a lack of composure. As such, the portrayal of gender ideals and constructs rely heavily on the media of which would become an established expectation that society either conforms to or deviates from.

\section{Personalised meaning of masculinity}

The overcoming of societal expectations and norms reflects non-conformance from the traditional gender, revealing the different constructs in existence and suggesting that gender meanings can be personalized to co-exist with existing societal expectations of gender [22, 25]. Findings suggest that gymnastics had increased participants' well-being physically (i.e. health and strength), emotionally (i.e. self-confidence) and psychologically (i.e. non-conformance to societal expectations in pursuit of personal interests). It was highlighted that the concept of gender had been imposed on them since the beginning of their gymnastics career. Responses received from outsiders generally focused on how a boy or a man ought to behave or the type of sport they should participate in. Through this, social construction of gender takes place with social and cultural practices influencing the behaviour moulding into society [46].

However, participants appeared not to internalised the external values and behaviours imposed. On the contrary, participants exhibited non-conformance from the traditional gender norms and pushed boundaries by pursuing a gender-inappropriate sport. Prior-entry into gymnastics showcased the participants' ignorance towards the societal construct of masculinity and the segregation of sport by their gender appropriateness. On the other hand, post-entry into gymnastics exhibited very personalised views on the construct of gender and masculinity entirely: an internalised belief that gender is not a medium for segregation; a conscious effort that gender is not an issue; and the extent of masculinity begins and ends internally. In spite of these views, participants displayed awareness that society has been moulded to think differently and to accept the importance of gender differences. The diversity of constructs and different thought-processes suggest that gender meanings can be personalised and exist to how one perceives the meanings.

\section{Conclusions}

Gymnastics is still known as a female-dominated sport with the stereotype of men displaying feminine traits or performing feminine activities due to the lack of knowledge society possesses. The purpose of this study is to investigate the experiences overcoming the stereotype of masculinity in Singaporean elite level male gymnasts. Many studies have ventured into the exploration of females in male-dominated sports yet there is a lack of research of males in female-dominated sports. Although this study is exploratory, results suggest that the concept of gender is initially learnt and eventually personalized into individually attached meanings. Prior-entry into gymnastics, participants reported ignorance of gender stereotypes manifested in sports. Masculinity was revealed to be a constructed and learned concept after exposure to different cultures, roles and norms constructed by the media. After overcoming societal expectations post-entry into gymnastics, participants exhibited non-conformance from the traditional gender norms of pursuing a gender-appropriate sport and held very personalized views on the construct of gender and masculinity, despite being aware of the established norms upheld in society. The acceptance of identity was manifested through the encapsulation of masculinised traits that emphasized conformity to society's definition of masculine, yet at the same time displayed unique views on gender constructs. The study provides a significant contribution to the concepts of sport and masculinity, through its investigation 
of Singaporean elite gymnasts within Singapore. The positive experiences can be used as a benchmark to incorporate and promote gender fluidity whereas negative experiences can be used as a platform for future changes of gender stereotypes in the realm of sports.

\section{Conflicts of Interest}

The authors declare no conflict of interest. All authors indicate that no benefits in any form have been received or will be received from a commercial party related directly or indirectly to the participant of this article.

\section{References}

1. Bailey R, Hillman C, Arent S, Petitpas A. Physical activity: An underestimated investment in human capital? J Phys Act Health. 2013; 10(3):289-308.

2. Bem SL. Gender schema theory: A cognitive account of sex typing. Psychol Rev. 1981; 88(4):354-364.

3. Billings AC, Eastman ST. Framing identities: Gender, ethnic, and national parity in network announcing of the 2002 Winter Olympics. J Comm. 2003; 53(4):569-586.

4. Chalabaev A, Sarrazin P, Fontayne P, Boiché J, Clément-Guillotin C. The influence of sex stereotypes and gender roles on participation and performance in sport and exercise: Review and future directions. Psychol Sport Exer. 2013; 14(2):136-144.

5. Clemens CF. Cultivation effects of media on perceptions of ideal masculinity and identity. [dissertation]. Storrs (CT): University of Connecticut, 2013.

6. Culver DM, Gilbert WD, Trudel P. A decade of qualitative research in sport psychology journals: 1990-1999. Sport Psychol. 2003; 17(1):1-15.

7. Dale GA. Existential phenomenology: Emphasizing the experience of the athlete in sport psychology research. Sport Psychol. 1996; 10(4):307-321.

8. Dorken S, Giles A. From ribbon to wrist shot: An autoenthnography of (a)typical feminine sport eevelopment. Women Sport Phys Act J. 2011; 20(1):13-22.

9. Drummond M. The social construction of masculinity as it relates to sport: An investigation into the lives of elite level athletes competing in individually-oriented masculinised sports. [dissertation]. Joondalup (WA): Edith Cowan University, 1995.

10. Eagleman AN. Constructing gender differences: newspaper portrayals of male and female gymnasts at the 2012 Olympic Games. Sport Soc. 2015; 18(2):234-247.

11. Elliott R, Fischer CT, Rennie DL. Evolving guidelines for publication of qualitative research studies in psychology and related fields. Brit J Clin Psychol. 1999; 38(3):215-229.

12. Feeley BT, Agel J, LaPrade RF. When is it too early for single sport specialization? Am J Sports Med. 2016; 44(1):234-241.

13. Festinger L. A theory of social comparison processes. Hum Relat. 1954; 7(2):117-140.

14. Gómez-López M, Gallegos AG, Extremera AB. Perceived barriers by university students in the practice of physical activities. J Sports Sci Med. 2010; 9(3):374.

15. Hardin M, Greer JD. The influence of gender-role socialization, media use and sports participation on perceptions of gender-appropriate sports. J Sport Beh. 2009; 32(2):207.

16. Hoffman R, Hattie JA, Borders LD. Personal definitions of masculinity and femininity as an aspect of gender self-concept. J Hum Couns. 2005; 44(1):66-83.

17. Knijnik JD, Horton P, Cruz LO. Rhizomatic bodies, gendered waves: transitional femininities in Brazilian Surf. Sport Soc. 2010;13(7-8): 1170-1185.

18. Koivula N. Ratings of gender appropriateness of sports participation: Effects of gender-based schematic processing. Sex Roles. 1995; 33(7):543-557.

19. Koivula N. Perceived characteristics of sports categorized as gender-neutral, feminine and masculine. J Sport Beh. 2001; 24(4):377.

20. Krane V, Choi PY, Baird SM, Aimar CM, Kauer KJ. Living the paradox: Female athletes negotiate femininity and muscularity. Sex Roles. 2004; 50(5-6):315-329.

21. Lantz CD, Schroeder PJ. Endorsement of masculine and feminine gender roles: Differences between participation in and identification with the athletic role. J Sport 
Beh. 1999; 22(4):545.

22. Lim JM, Kwon SY, Lim SW. Qualitative approach about gender-role identity of professional male dancers in modern dance. Korean J Phys Educ. 2012; 51(5): 603614.

23. Matteo S. The effect of gender-schematic processing on decisions about sex-inappropriate sport behavior. Sex Roles. 1998; 18(1):41-58.

24. Mennesson, C. 'Hard' women and 'soft' women: The social construction of identities among female boxers. Int Rev Sociol Sport. 2000; 35(1):21-33.

25. Park JY. Gender identity of male athletes in female leading sports. [dissertation]. Seoul: Sookmyung Women's University, 2007.

26. Petlichkoff LM. Youth sport participation and withdrawal: Is it simply a matter of fun?. Pediatr Exerc Sci. 1992; 4(2):105-110.

27. Pfister G. Women in sport - gender relations and future perspectives. Sport Soc. 2010; 13(2):234-248.

28. Riemer BA, Visio ME. Gender typing of sports: an investigation of Metheny's classification. Res Q Exerc Sport. 2003; 74(2):193-204.

29. Roster CA. "Girl power" and participation in macho recreation: The case of female harley riders. Leisure Sci. 2007; 29(5):443-461.

30. Sabo D. Sport, patriarchy, and male identity: New questions about men and sport. Arena Rev. 1985; 9(2):1-30.

31. Sandelowski M. Sample size in qualitative research. Res Nurs Health. 1995; 18(2):179-183.

32. Scanlan TK, Carpenter PJ, Simons JP, Schmidt GW, Keeler B. An introduction to the sport commitment model. J Sport Exerc Psychol. 1993; 15(1):1-15.

33. Schmalz DL, Kerstetter DL. Girlie girls and manly men: chidren's stigma consciousness of gender in sports and physical activities. J Leisure Res. 2006; 38(4):536-557.

34. Scraton S, Fasting K, Pfister G, Bunuel A. It's still a man's game?: The experiences of top-level european women footballers. Int Rev Sociol Sport. 1999; 34(2):99-111.

35. Sisjord MK, Kristiansen E. Elite Women wrestlers' muscles: Physical strength and a social burden. Int Rev Sociol Sport. 2009; 44(2-3):231-246.
36. Slater A, Tiggemann M. Gender differences in adolescent sport participation, teasing, self-objectification and body image concerns. J Adolesc. 2011; 34(3):455-463.

37. Vuori I. Exercise and physical health: Musculoskeletal health and functional capabilities. Res Q Exerc Sport. 1995; 66(4):276.

38. Young K, White P, McTeer W. Body talk: Male athletes reflect on sport, injury, and pain. Soc Sport J. 1994; 11(2):175-194.

39. Butler J. Gender trouble: Feminism and the subversion of identity: Routledge, 2011.

40. Charmaz K. Constructing grounded theory: A practical guide through qualitative analysis. Thousand Oaks (CA): Sage Publications, 2006.

41. Connell RW. Masculinities. Oakland (CA): University of California Press, 1995.

42. Creswell JW. Qualitative inquiry and research design: choosing among five traditions. Thousand Oaks (CA): Sage Publications, 1998.

43. Gerbner G, Gross L, Morgan M, Signorielli N, Shanahan J. (2002). Growing up with television: Cultivation processes. In: Bryant J, Zillmann D, editors. Lea's communication series. Media effects: Advances in theory and research. Mahwah (NJ): Lawrence Erlbaum Associates Publishers, 2002. P. 43-67.

44. Husserl E. Ideas: General introduction to pure phenomenology. London: Routledge, 2015.

45. Kay T, Jeanes R. Women, sport and gender inequity. In: Houlihan B, editor. Sport and society: A student introduction. Thousand Oaks (CA): Sage Publication, 2008. P. 130-154.

46. Lorber, J. E., \& Farrell, S. A. (1991). "Night to his Day": The social construction of gender. In: Lorber J, editor. Paradoxes of Gender. New Haven (CT): Yale University Press, 1991

47. Messner MA. Power at play: Sports and the problem of masculinity: Boston (MA): Beacon Press, 1992.

48. Messner MA, Sabo DF. Sex, violence \& power in sports: Rethinking masculinity. Freedom (CA): Crossing Press, 1994.

49. Morehouse RE, Maykut P. Beginning qualitative research: 
A philosophical and practical guide. London: Routledge, 2002.

50. Morgan, M., Shanahan, J., \& Signorielli, N. (2009). Growing up with television: Cultivation processes.

51. Moustakas CE. Phenomenological research methods. Thousand Oaks (CA): Sage Publications, 1994.

52. Nesti M. Existential psychology and sport: Theory and application: London: Routledge, 2004.

53. Patton MQ. Qualitative research \& evaluation methods.
Thousand Oaks (CA): Sage Publications, 2002.

54. Sabo DF, Runfola R. Jock: Sports and Male Identity. NewJersey: Prentice Hall Direct, 1980.

55. Whitson D, Messner MA, Sabo DF. Sport, men, and the gender order: Critical feminist perspectives. Champaign (IL): Human Kinetics, 1990

56. Wolcott HF. Transforming qualitative data: Description, analysis, and interpretation: Thousand Oak (CA): Sage Publications, 1994. 